RESEARCH ARTICLE

\title{
Epidemiology of Primary Anterior Cruciate Ligament Ruptures in Men and Women
}

\author{
María CASADO ${ }^{1}$, Roberto SEIJAS ${ }^{1-3}$, Albert PÉREZ-BELLMUNT ${ }^{*}$, Raul NAVARRO $^{1}$, Paolo RAGAZZI ${ }^{1}$ and \\ Pedro ALVAREZ $Z^{1-4}$
}

${ }^{1}$ Anatomy Unit, International University of Catalonia, Barcelona, Spain

${ }^{2}$ Fundación García-Cugat, Barcelona, Spain

${ }^{3}$ GC Arthroscopy, Quirón Hospital, Barcelona, Spain

${ }^{4}$ Mutuality Catalan Footballers, Spanish Football Federation, Barcelona, Spain

*Corresponding author: Albert PÉREZ-BELLMUNT, Anatomy Unit, Campus of Salut, International University of Catalonia, C/Josep Trueta s/n CP 08195, Sant Cugat del Vallès, Barcelona, Tel: +34-93-504-20-14

\begin{abstract}
In the practice of sports that require impact and pivot movements such as football or skiing, knee injuries are common and among these is important to underline the rupture of the Anterior Cruciate Ligament (ACL). Noncontact movements cause a $70 \%$ of $A C L$ injuries and there is a high incidence of ruptures in women. Therefore, the objective of this study is to analyse what are the causes for the difference in incidence between men and women in terms of $\mathrm{ACL}$ ruptures. Through the search in the previous literature it has been observed that the fact that female athletes suffer $A C L$ injuries with a higher frequency than male athletes is mainly due to anatomical, hormonal, biomechanical and neuromuscular control factors. Due to this occurrence, it is important to promote mainly treatments and prevention plans in order to reduce neuromuscular imbalances, that is predominant in women, to decrease the risk of $A C L$ injuries in female athletes.
\end{abstract}

\section{Introduction}

The rupture of the anterior cruciate ligament is one of the most common injuries among athletes. According to the Clínica Centro de Madrid, football, baseball, basketball and skiing account for $78 \%$ of the anterior cruciate ligament injuries. Most of these injuries are caused by efforts made during the practice of exercises that involves pivoting, braking or impact movements [1].
The rupture of knee ligaments represents the $12 \%$ of the most common injuries in football, preceded by muscle tears $(14 \%)$ and followed by meniscus and cartilage injuries (6.3\%) [2].

The ACL lesion is usually produced by non-contact movements $[3,4]$, which means that is caused by biomechanical errors and a poor neuromuscular control. It has been demonstrated that the incidence of this type of injury is greater in women than in men. Female athletes have a 4 to 6 times higher risk than men to suffer this kind of injury [5].

Several factors, anatomical as well as hormonal, biomechanical or related to neuromuscular control, are the cause of the predominance of the lesion in women [6].

Due to this striking occurrence we have decided to make a comparison between the different articles that treat the $A C L$ injury in both male and female athletes. In this way we seek to be able to answer and put together the different hypotheses about the causes and factors that determine the singular circumstance of the aforementioned injury.

\section{Material and Methods}

In June 2018 a search of articles related to ACL injuries was made, it has been done in different databases 
such as PubMed, SAGE journals, Journal of Orthopedic \& Sport Physical Therapy (JOSPT) or DiVA. In the search, the sentence "comparison of ACL injury between women and men" was used. From this search emerged a large set of articles related to injuries in women and men, especially associated to football (Figure 1).

From this search we obtained 24 articles, which were interesting for considering the differences be- tween men and women in ACL injuries. Once all the articles were read, eight of them were discarded. In those selected it was possible to verify that much of the information they contained coincided.

The coincidences between the different articles confirmed the possible causes of the greater female incidence in the ACL lesion. Finally, we focused our investigation in those articles that gave a better
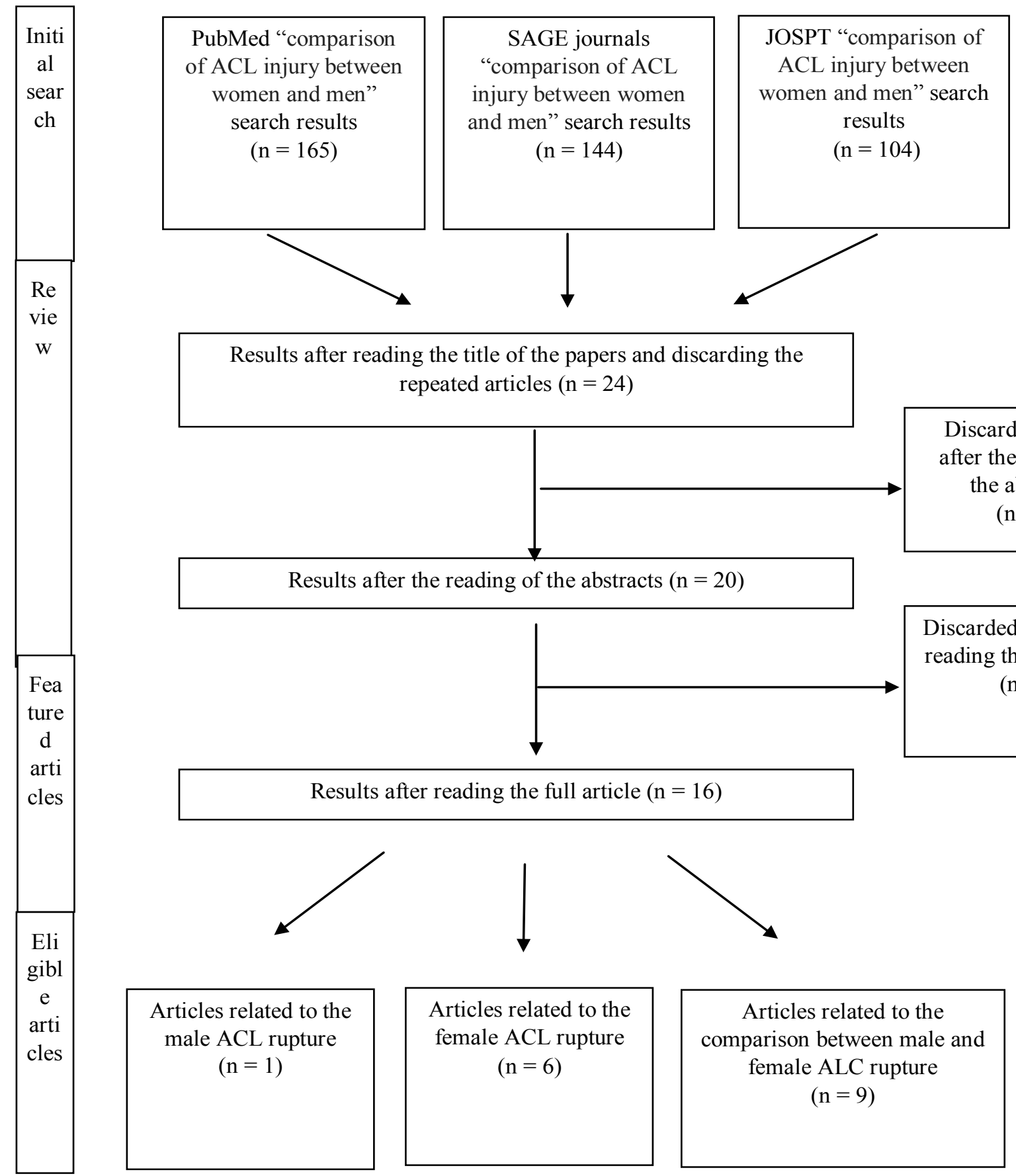

Results after reading the title of the papers and discarding the repeated articles $(\mathrm{n}=24)$
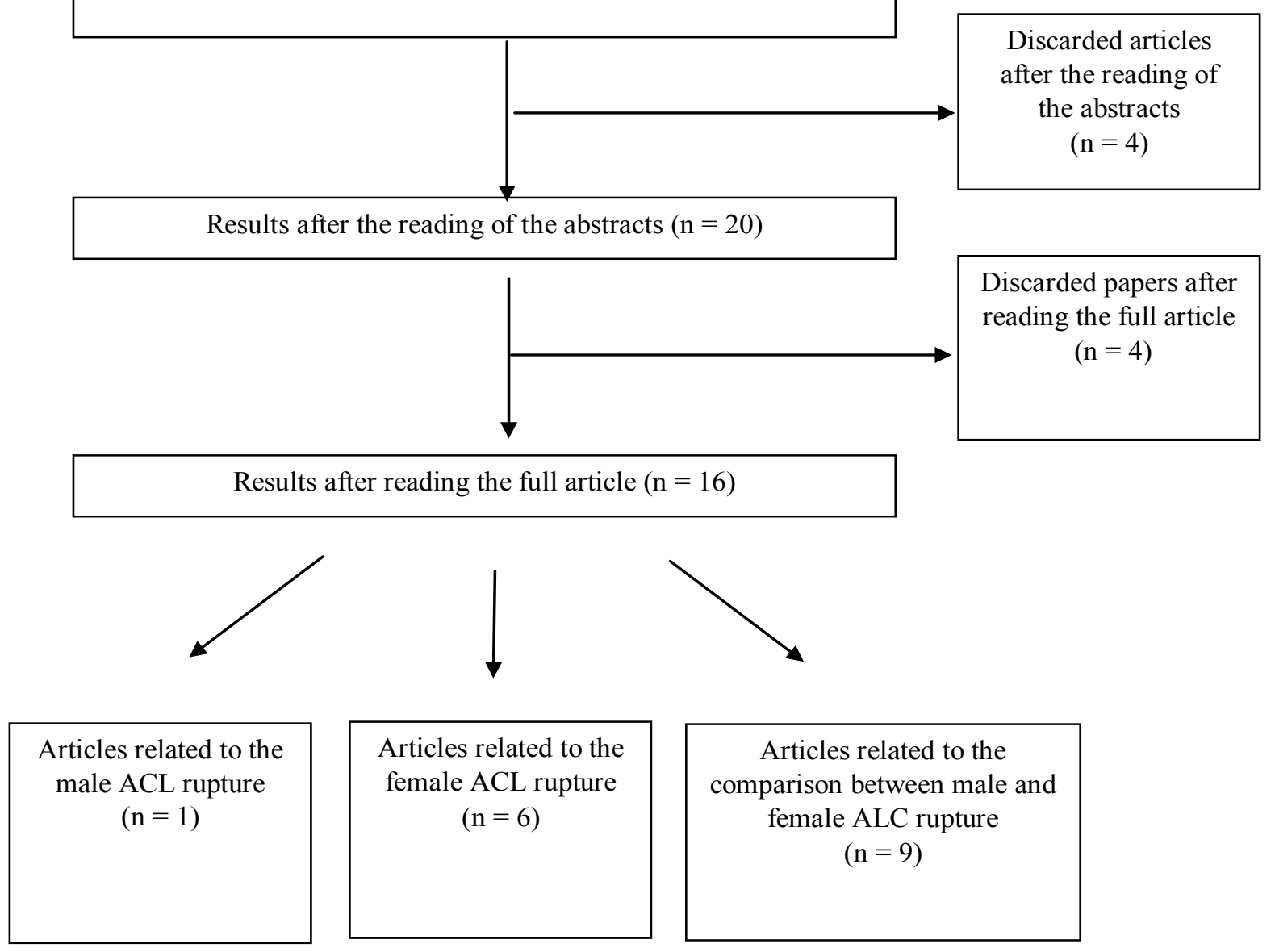

Featured articles among the selected for being more relevant to the treated topic $(\mathrm{n}=3)$

Figure 1: Summary of the article's selection. 
Table 1: Characteristics of the studies and common points between these.

\begin{tabular}{|c|c|c|c|c|c|}
\hline Author & Year & $\mathbf{n}$ & $\begin{array}{l}\text { Gender } \\
\text { (M/W) }\end{array}$ & $\begin{array}{l}\text { Average Age } \\
\text { (M/W and total) }\end{array}$ & Fragments of interest \\
\hline \multirow[t]{7}{*}{ Harmon KG, et al. [6] } & \multirow[t]{7}{*}{2000} & \multirow{7}{*}{\multicolumn{3}{|c|}{ Compilation of articles }} & Female increased predisposition to $A C L$ ruptures \\
\hline & & & & & Intrinsic factors: \\
\hline & & & & & Ligamentous laxity \\
\hline & & & & & $\begin{array}{l}\text { Hormonal influences (more ACL laxity at progesterone } \\
\text { and estrogen peaks, increased laxity in pregnancy and in } \\
\text { ovulatory phase) }\end{array}$ \\
\hline & & & & & $\begin{array}{l}\text { Biomechanical alignment (more femoral anteversion, } \\
\text { larger Q-Angle, increased external tibial torsion, more } \\
\text { overpronation, an increased thigh-foot angle) }\end{array}$ \\
\hline & & & & & Extrinsic factors: \\
\hline & & & & & $\begin{array}{l}\text { Conditioning, experience, skill, muscle strength and } \\
\text { recruitment and hamstring activation. }\end{array}$ \\
\hline \multirow[t]{5}{*}{ Dugan SA [7] } & \multirow[t]{5}{*}{2005} & \multirow{5}{*}{\multicolumn{3}{|c|}{ Compilation of articles }} & Female higher risk than men \\
\hline & & & & & $\begin{array}{l}\text { Sex hormones and menstrual cycle (higher risk follicular } \\
\text { and ovulatory phase) }\end{array}$ \\
\hline & & & & & Anatomic consideration (Q-Angle, joint laxity, ...) \\
\hline & & & & & $\begin{array}{l}\text { Dynamic neuromuscular imbalances (differences in } \\
\text { landing and other movement strategies) }\end{array}$ \\
\hline & & & & & $\begin{array}{l}\text { Neuromuscular patterns (same incidence in dominant } \\
\text { and non-dominant knee, quadriceps-dominant pattern in } \\
\text { females) }\end{array}$ \\
\hline \multirow[t]{2}{*}{ Fayad LM, et al. [8] } & \multirow[t]{2}{*}{2008} & \multirow[t]{2}{*}{63} & \multirow[t]{2}{*}{$33 / 30$} & $-/-$ & Females 2 to 8 times higher risk of $A C L$ tears \\
\hline & & & & (43) & $\begin{array}{l}\text { Anatomic consideration: Smaller females' cross-sectional } \\
\text { area, smaller femoral intercondylar notch width in women, } \\
\text { also females have a smaller ACL volume than males and } \\
\text { differences in Q-Angle. }\end{array}$ \\
\hline \multirow[t]{2}{*}{ Park SK, et al. [9] } & \multirow[t]{2}{*}{2009} & \multirow{2}{*}{\multicolumn{3}{|c|}{26 healthy women (unknown age) }} & Greater laxity during ovulation \\
\hline & & & & & Reduction in knee stiffness during ovulation \\
\hline \multirow{4}{*}{$\begin{array}{l}\text { Boguszewski DV, et } \\
\text { al. [10] }\end{array}$} & \multirow[t]{4}{*}{2015} & \multirow[t]{4}{*}{47} & \multirow[t]{4}{*}{$22 / 25$} & $34.6 / 28.4$ & $70 \%$ ACL ruptures by non-contact situations \\
\hline & & & & $(31.5)$ & Females 2 to 8 times higher risk of $A C L$ injuries than male \\
\hline & & & & & Increased joint laxity \\
\hline & & & & & Reduced knee stiffness \\
\hline \multirow[t]{4}{*}{ Larruskain J, et al. [11] } & \multirow[t]{4}{*}{2017} & \multirow[t]{4}{*}{85} & \multirow[t]{4}{*}{$50 / 35$} & $25 / 25$ & Contact injuries higher for men \\
\hline & & & & $(25)$ & For ACL ruptures five times more common in women \\
\hline & & & & & $\begin{array}{l}\text { Severe injuries of knee and ankle ligament more frequent } \\
\text { in women }\end{array}$ \\
\hline & & & & & $\begin{array}{l}2-3 \text { times higher risk of } A C L \text { ruptures in women than men } \\
\rightarrow \text { differences in biomechanics and neuromuscular control }\end{array}$ \\
\hline \multirow[t]{5}{*}{ Schilaty ND, et al. [5] } & \multirow[t]{5}{*}{2018} & \multirow[t]{5}{*}{39} & \multirow[t]{5}{*}{$19 / 20$} & \multirow{5}{*}{$\begin{array}{l}43.1 / 40.0 \\
(41.55)\end{array}$} & Female higher risk than men \\
\hline & & & & & Non-contact injury \\
\hline & & & & & Biomechanics changes \\
\hline & & & & & Neuromuscular control \\
\hline & & & & & $\begin{array}{l}\text { Sex differences: kinematics, stiffness and recruitment } \\
\text { strategies. }\end{array}$ \\
\hline
\end{tabular}

comparison between men and women, in addition to those that expose the possible causes of increased risk of $A C L$ injuries in women.

\section{Results}

\section{Characteristics of the articles}

Some of the selected articles do not refer to a specific study, but they are rather a collection of a set of previously conducted studies. These articles give a more generalized and global view of the analyzed subject (Table 1).

They also show the possible studied causes of why women have a greater risk of suffering a rupture of the anterior cruciate ligament. Many of them coincide in 
the two selected articles that have the aforementioned characteristics $[6,7]$.

On the other hand, we find a series of studies that refer to a specific investigation, so they focus on a specific area of the global issue that is the difference in $\mathrm{ACL}$ rupture between men and women.

In the case of the oldest of the five individual studies, anatomic differences between men and women are analysed [8]. In the second one, of 2009, they treat the laxity of the ligaments and stiffness of the knee joint related to the menstrual cycle of 26 women [9]. The article of 2015 deals with the same topic but in general terms, without considering the menstrual cycle and only comparing men and women [10].

Finally, we find the studies conducted in 2018 and 2017, the most recent articles in which there is a more general view and the causes coincide on the types of injuries that predominated between men and women $[5,11]$.

\section{Characteristics of the samples}

Only five of the selected articles give information about the subjects chosen for the study. This happens because the other two articles are a collection of studies, so they do not specify the information about the patients (Table 1).

Two of the studies used corpses to carry out the research, in one of them the average age is 41.55 [5] while in the other one is 31.5 [10]. For the study conducted in 2017, 85 athletes with an average age of 25 were selected [11]. In the one about the menstrual cycle related to laxity and stiffness, 26 healthy women were selected for the study, of which we don't know the age because it was not mentioned in the article [9]. Finally, the 2008 article was conducted with 63 patients of 43 years of average age, who were undergoing examination for knee pain [8].

\section{Results obtained from the analysed studies}

From the comparison of the different articles, we have observed that there is an agreement in affirming that women have a greater risk in suffering ruptures of the anterior cruciate ligament. Being this injury mainly produced not by contact but by the incorrect movement of the athlete (Table 1).

Among the causes of this circumstance, the most common are the biomechanical differences between men and women, such as the realization of different movements during sports, in addition to the different neuromuscular control that also raises the injury incidence in women.

Regarding the anatomical features in women, there is a predominance of ligament laxity, which increases during ovulation and stiffness of the knee joint that decreases during the same menstrual period [9]. The incidence of the menstrual cycle is due to the hormonal influence that increases estrogen and progesterone from the ovulation period until the follicular phase $[6,7]$.

Finally, another anatomical difference to highlight between men and women is the $Q$ angle, which increases the women predominance in this type of injury $[6,7]$. This angle is formed by two lines, one that goes from the Anterior Superior lliac Spine (ASIS) to the mid-point of the patella and the other one that goes from the midpoint of the patella to the tibial tubercle. Due to the wider pelvis in women, the $Q$ angle is bigger, and the chances of an ACL rupture are greater [12].

\section{Discussion}

The rupture of the anterior cruciate ligament is not one of the most prevalent injuries in the population, but it has a high incidence in that part of the population that practice sports such as football or skiing, and especially in the case of professional athletes.

For example, football is one of the most practiced sports in the world and $10 \%$ of professionals are women [13]. As the ACL injury is one of the most prevalent in this sport, it has been studied in its complexity and it has been determined why it affects mainly female players. By carrying out different studies on this occurrence, it can be demonstrated that the differences between genders as the anatomical one along with neuromuscular control, epidemiological, training and conditions of the athletes are the reason why women have a higher risk of suffering this injury.

Having women, a 4 to 6 times higher risk than men to suffer an ACL injury [5], there is a wide range of articles that discuss the possible causes of this fact. The objective of this article is to choose a set of articles dealing with this topic and by making a comparison between them, get to the conclusion of why this injury occurs with greater incidence in women.

One of the most useful ways we have found to classify the causes of the injury is to separate them into extrinsic and intrinsic factors. The extrinsic factors are related with the type of sport, the environment and the conditions of the athlete. None of them shows the possible difference between men and women regarding this injury. It does accentuate the fact that fatigue is responsible for a greater range of injuries between players and that the different use of the muscles is also a possible cause of the differences [6].

For example, in the case of male players, during the exercise they tend to activate with more frequency the hamstrings, whose contraction protects the ACL. In contrast, in the female exercise, the activation of the quadriceps and gastrocnemius predominates. One of the possible ways to prevent the injury would be to promote the activation of the hamstrings against the predominance of quadriceps and gastrocnemius in female athletes $[6,7,14]$. 
On the other hand, intrinsic factors seem to have more importance in justifying the possible causes of why women suffer more ACL ruptures. These factors could be classified into anatomical differences, hormonal influence, biomechanical differences and distinguished neuromuscular control between men and women.

To begin with the anatomical differences, we found a crossing area of ligaments between femur and tibia that is smaller in women than in men, in addition to a lower ACL volume in women [8]. These characteristics are supposed to increase the ligament laxity that is also accentuated by the hormonal influence during the menstrual cycle of the women. During the ovulation and follicular phases, the increase of progesterone and estrogen could suppose an increase of the laxity and a reduction of the stiffness of the joint increasing this way the risk of $A C L$ rupture $[6,7,15]$.

Another of the anatomical differences between women and men, which goes hand to hand with the biomechanical causes is the $\mathrm{Q}$ angle, that is greater in women for having a larger pelvis, as previously described at the end of the results section. This characteristic tends to increase medial stress on the knee ligaments [12]. Therefore, those athletes who have an increased $Q$ angle are more likely to suffer an ACL rupture.

Finally, according to some studies made by McLean, it is possible to verify that as a biomechanical factor related to neuromuscular control, in female subjects stopping quickly after running, there is a delay in the activation of the hamstrings compared to the quadriceps, as previously explained. This event involves a greater anterior displacement of the tibia and a pronounced valgus in the knees, which increases the stress on the ACL [12].

After this evaluation, being able to verify that women have a greater risk in this type of injury, it would be necessary to increase the prevention, especially in sports, and decrease the neuromuscular imbalances [16], such as the predominant use of the dominant leg or quadriceps, increasing the conditioning of the hamstrings [15]. In addition, it is important to improve the techniques of turns and pivots that cause torsional damage, as well as deceleration techniques, such as landing after a jump or a sudden stop.

In conclusion, the anatomical, biomechanical and neuromuscular control aspects that differentiate women and men are the ones that demonstrate the best, that female athletes have a greater risk of suffering an anterior cruciate ligament injury.

\section{References}

1. Rotura de LCA en mujeres (2018) Grupo sobre entrenamiento [en línea]. 30 de agosto de.

2. Shalaj I, Tishukaj F, Bachl N, Tschan H, Wessner B, et al. (2016) Injuries in professional male football players in Kosovo: a descriptive epidemiological study. BMC Musculoskelet Disord 17: 338.

3. Junge A, Dvorak J (2007) Injuries in female football players in top-level international tournaments. Br J Sports Med 1: 3-7.

4. Faude O, Junge A, Kindermann W, Dvorak J (2005) Injuries in female soccer players: a prospective study in the German national league. Am J Sports Med 33: 1694-1700.

5. Schilaty ND, Bates NA, Nagelli C, Krych AJ, Hewett TE (2018) Investigation performed at the Mayo Clinic, Rochester, Minnesota, USA. Sex-Based Differences in Knee Kinetics with Anterior Cruciate Ligament Strain on Cadaveric Impact Simulations.

6. Harmon KG, Ireland ML (2000) Gender differences in noncontact anterior cruciate ligament injuries. Clin Sports Med 19: 287-302.

7. Dugan SA (2005) Sports-Related Knee Injuries in female athletes: what gives? Am J Phys Med Rehabil 84: 122-130.

8. Fayad LM, Rosenthal EH, Morrison WB, Carrino JA (2008) Anterior Cruciate Ligament Volume: Analysis of Gender Differences. J Magn Reson Imaging 27: 218-223.

9. Park SK, Stefanyshyn DJ, Loitz-Ramage B, Hart DA, Ronsky $\mathrm{JL}$ (2009) Changing Hormone Levels during the Menstrual Cycle Affect Knee Laxity and Stiffness in Healthy Female Subjects. Am J Sports Med 37: 588-598.

10. Boguszewski DV, Cheung EC, Joshi NB, Markolf KL, McAllister DR (2015) Male-Female Differences in Knee Laxity and Stiffness: A Cadaveric Study. Am J Sports Med 43: 2982-2987.

11. Larruskain J, Lekue JA, Diaz N, Odriozola A, Gill SM (2017) A comparison of injuries in elite male and female football players: A five-season prospective study. Scand J Med Sci Sports 28: 237-245.

12. Ángulo-Q de la rodilla (2018) Bulevip [en línea]. 30 de agosto de.

13. Waldén M, Hägglund M, Werner J, Ekstrand J (2011) The epidemiology of anterior cruciate ligament injury in football (soccer): a review of the literature from a gender-related perspective. Knee Surg Sports Traumatol Arthrosc 9: 3-10.

14. Hurd WJ, Axe MJ, Snyder-Mackler L (2008) Influence of Age, Gender, and Injury Mechanism on the Development of Dynamic Knee Stability After Acute ACL Rupture. J Orthop Sports Phys Ther 38: 36-41.

15. Waldén M, Hägglund M, Magnusson H, Ekstrand J (2011) Anterior cruciate ligament injury in elite football: a prospective three-cohort study. Knee Surg Sports Traumatol Arthrosc 19: $11-19$.

16. Henry JC, Kaeding C (2001) Neuromuscular differences between male and female athletes. Curr Womens Health Rep 1: 241-244.

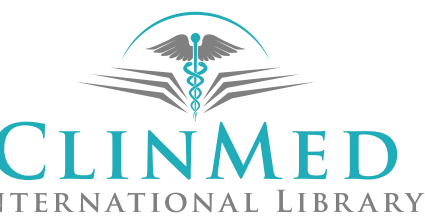

